\title{
THE EFFECT OF LENSES AND LIGHT ON THE GREEN PLANT IMAGING USING MODIFYING CONFOCAL MICROSCOPE
}

\author{
Mashaer Abdarahim HUSSEIN NASR ${ }^{1,4}$, Hassan Hamed ABUELHASSAN ABDALLA ${ }^{1}$, \\ Abdelsaki Suliman MOHAMMED HAMID ${ }^{2}$, Abdelfatah Mohammed MOHAMMED \\ $\mathrm{AHMED}^{3}$, Adam Abdalla ELBASHIR ADAM ${ }^{1,4}$

\footnotetext{
${ }^{1}$ ALneelain University Faculty of science and technology - Department of Electronics and Computation Physics

${ }^{2}$ ALneelain University Faculty of science and technology -department of laser Physics
} \\ ${ }^{3}$ ALneelain University Faculty of science and technology- department of Medical Physics, Albaladya Street, Khartoum Sudan \\ ${ }^{4}$ Future University Faculty of Engineering -Department of Electronics engineering, Africa Street, Khartoum Sudan
}

\begin{abstract}
Image processing becomes one of the most important demands, requisites and exigencies in the 20th century, because of its usages in many and different parts of habitats and customs, so the enhanced image represents the main issue for scientists and researchers, where little methods, devices and programs were existing. According to this, our study was significantly concerned with the image processing; namely, the living cell imaged using different lenses on the confocal microscopy. The microscope was designed very well to give perfect resolution imaged taken from different situation (angles) and different lenses with the magnification ( $X=40,100$ and 160) and various light sources (white light, laser red, laser blue, and laser green). From the results conducted and achieved it's clear that the lens with magnification 100 and near wavelength light color gives more information about the living cell (object). The histograms confirm vigorously these results, so this could solve and enhanced the resolution image in multi disciplines, scopes and avenues.
\end{abstract}

Keywords: lenses, light, confocal microscopy, living cell, origin program, histogram, image processing.

\section{Introduction}

Digital image processing is defined as a mathematical manipulation of an information image to modify or improve it in some way. Interminably, using of computers to deploy and disseminate a digital image (i.e., digital image processing) was something achieved by a single moderated slight cluster of experts who has an admission to those equipment exclusively [1]. Typically, and widely, this grouping of specialists and equipment's were only creating and modelling them with their highly perseverance investigations in labs, and so the arena of digital image processing has its origins in the academic monarchy. Nowadays, however, the grouping of an influential computer on each desktop and the detail that closely everybody has some kind of device for digital image gaining. Therefore, a cell phone camera, digital camera, or scanner, has occasioned in an overabundance of digital images and, with that, the great numerous and huge digital image processing has been developed as combined as expression processing [2, 3].

It was renowned that several years back the photo's digitizing and their redeemable to a file on a computer was an inefficient duty. This is perhaps, stiff to imagine, assumed today's prevailing hardware and operating system level provision for all sorts of digital broadcasting, but 
it is continuously sobering to reminisce that "personal" computers in the initial 1990s were not powerful adequate to even load bent on principal nostalgia a single image from a distinguishing digital camera presently. At the present influential hardware and software packages ought to prepare it possible intended for amateurs to use digital images and videos fair as simply as specialists $[4,5]$.

Altogether, of these growths, must affect in a large community that works productively with digital images though consuming only an elementary sympathetic of the fundamental mechanics. Aimed at the characteristic consumer, just deficient to generate a digital store of vacation photos, a profounder understanding is not obligatory, just as a deep understanding of the burning engine is needless to effectively drive a car $[6,7]$.

In the present day, IT experts necessity be additional than solely acquainted with digital image processing. They are predictable to be able to intelligently operate images and associated digital media, which are progressively significant part of the workflow not only of those elaborate in medicine and the media but all manufacturing. In the similar way, software engineers and computer scientists are gradually challenged with unindustrialized programs, databases, and related systems that must properly contract through digital images [7].

Histograms are rummage-sale to portray image statistics in a simply understood visual setup. With a histogram, it is laid-back to determine certain types of problems in an image, for example, it is modest to accomplish it if an image is correctly exposed by visual examination of its histogram $[8,9]$.

Actually, histograms are so important, impressed and valuable that modern digital cameras regularly deliver a real-time histogram connection on the viewfinder to assistance avoid captivating poorly exposed pictures. It is more significant to fastening faults similar to the image imprisonment stage since poor exposure consequences in an enduring beating of data, which it is not conceivable to recuperate far along by means of image-processing techniques $[10,11]$. Furthermore, to their practicality throughout image capture, histograms are also rummage-sale later to recover the visual form of an image and as a "forensic" tool for defining what sort of dispensation has formerly been useful to an image [12-14]. While referring and mentioning to histograms of color images, characteristically what is intended is a histogram of the image strength (luminance) or of the separate color channels. Both of these alternatives are consolidated and reinforced by almost each image-processing request and are used to empirically evaluate the image excellence, especially straight after image gaining [15, 16, 17].

\section{Experimental part}

The object was chosen from the department of biology faculty of Science and Technology ALneelain University as a living cell (green plant sample). The confocal microscopy was modified very well to give an obvious image from different situation of (angles). Then the sample (object) was put intentionally and carefully in front of the modified confocal microscopy, after that the image was taken using a CCD camera with different lenses and different lights. The images were next introduced to the origin lab program. And, then finally was analyzed with histogram. The results of modified confocal microscopy images compared with normal microscope images (reference).

\section{Results and Discussions}

It's well-known that the image can be build up using point by point processing in confocal imaging system; this method is suitable and easy for the image to be digitized and processing. Moreover, in confocal system the image of any object providing a range of information which can be visualized an understanding three dimensions (3D). Here, a green plant sample was putting carefully in front of the modified confocal microscopy which have different lenses with the 
magnification ( $X=40,100$ and 160) and different lights (white light, laser red, laser blue, and laser green), and then, four green plant images were taken using a CCD camera. The results of modified confocal microscopy images compared with normal microscope images (reference). to Fig. (5).

Accordingly, all the images taken were presented as in the following figures from Fig. (1)
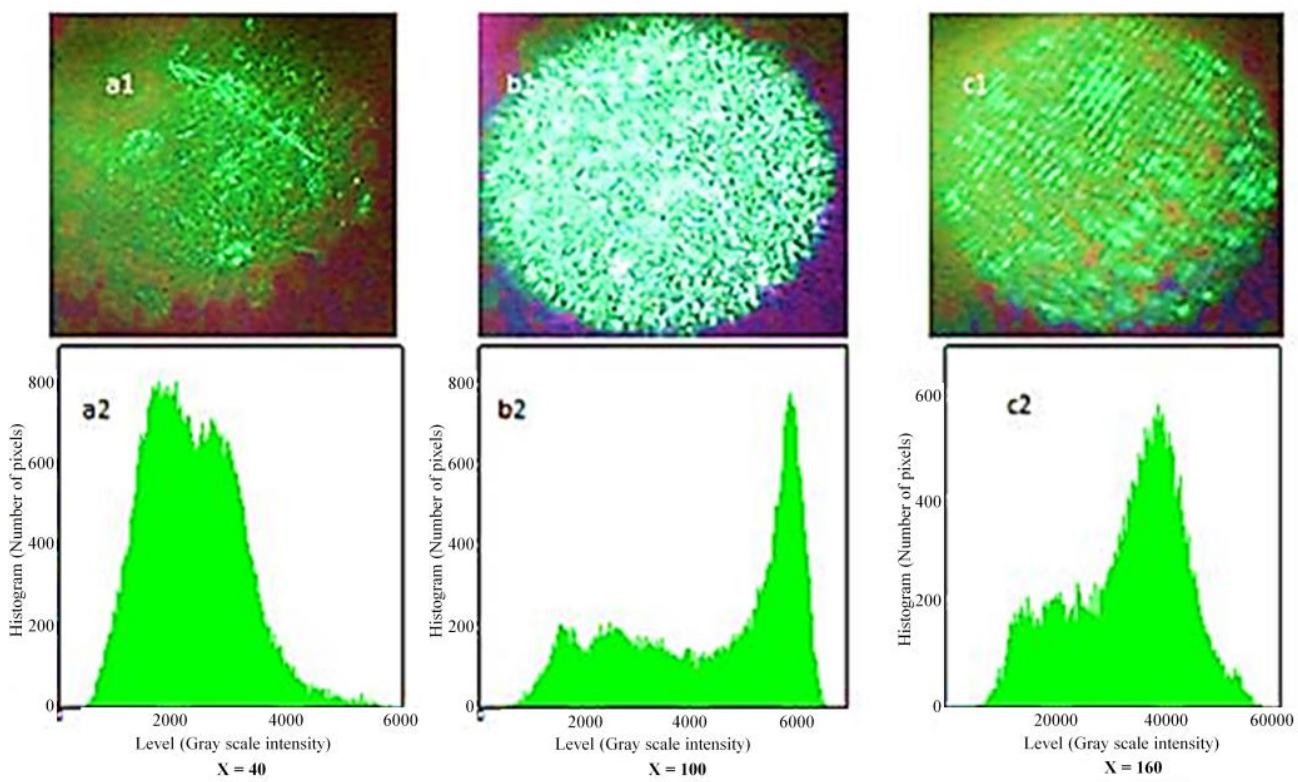

Fig. 1. The green light images of the plant microstructure at different magnifications: a1) X40; a2) X40 histogram, b1) X100; b2) X100 histogram, c1) X160; c2) X160 histogram
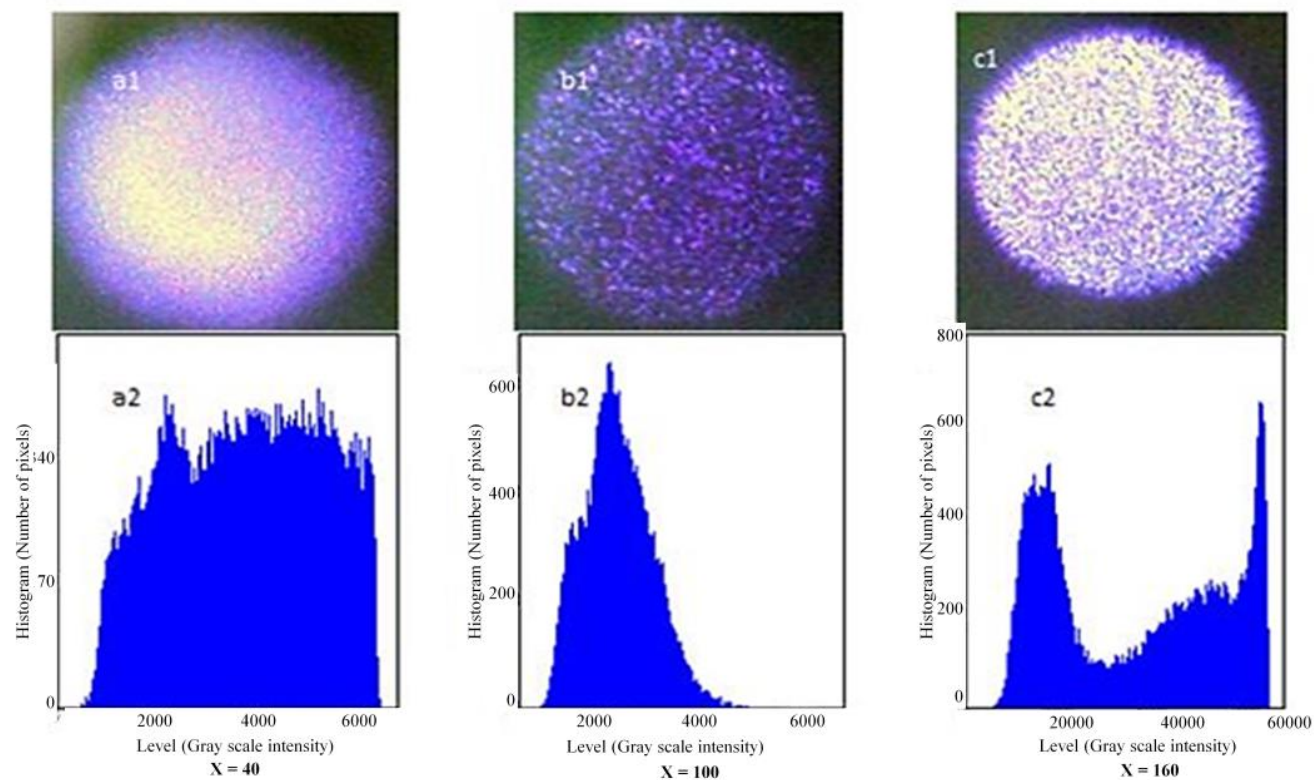

Fig. 2. The blue light images of the plant microstructure at different magnifications: a1) X40; a2) X40 histogram, b1) X100; b2) X100 histogram, c1) X160; c2) X160 histogram 

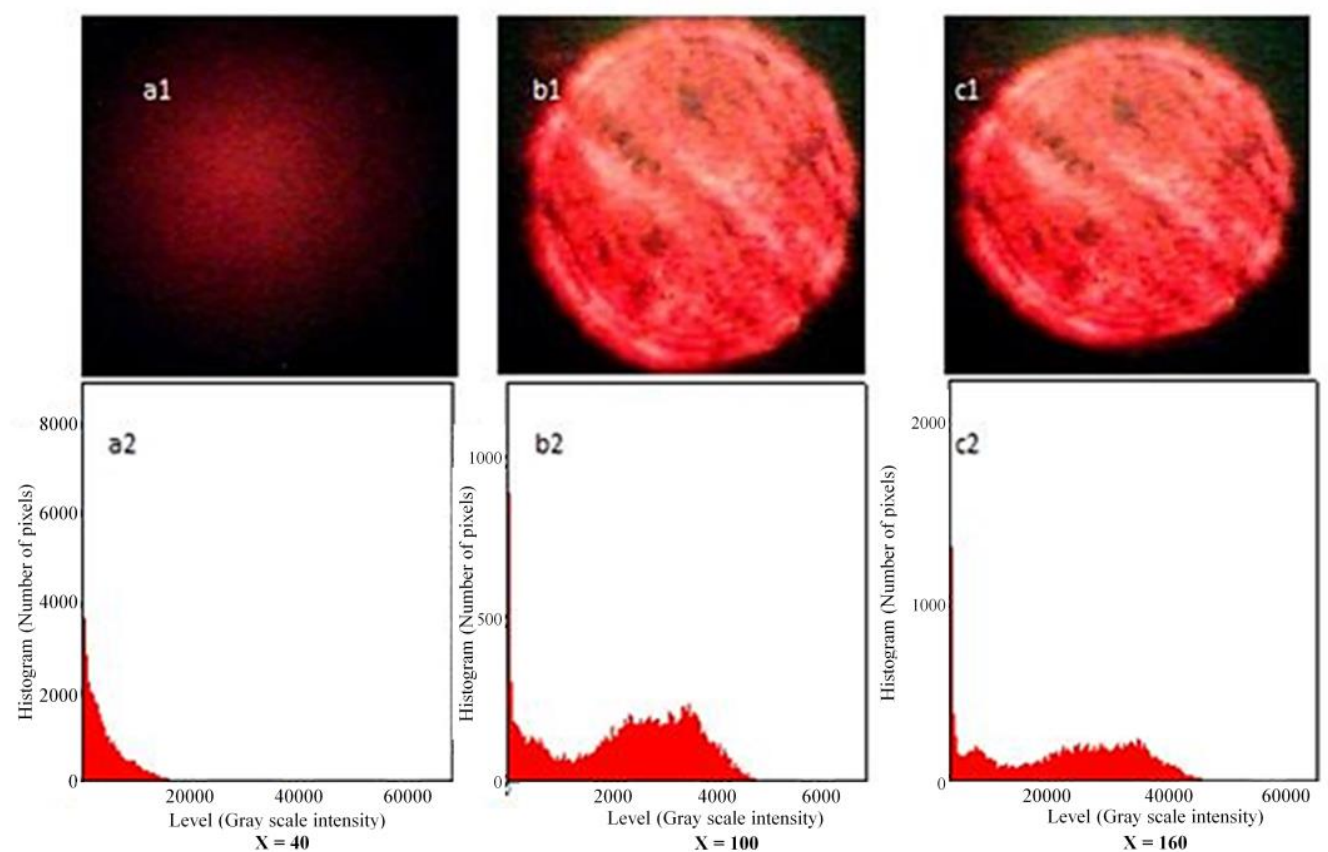

Fig. 3. The red-light images of the plant microstructure at different magnifications:

a1) X40; a2) X40 histogram, b1) X100; b2) X100 histogram, c1) X160; c2) X160 histogram
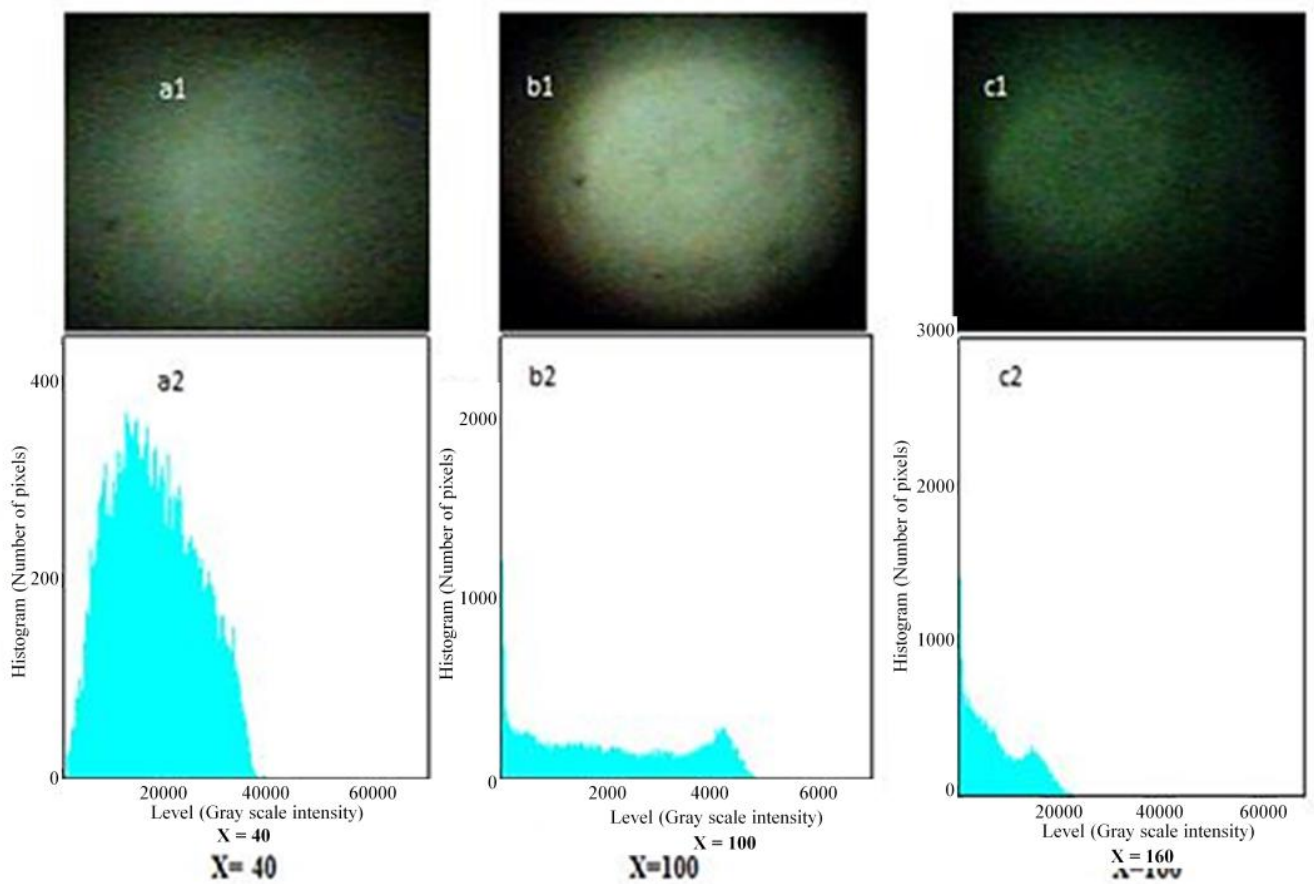

Fig. 4. The white light images of the plant microstructure at different magnifications:

a1) X40; a2) X40 histogram, b1) X100; b2) X100 histogram, c1) X160; c2) X160 histogram 

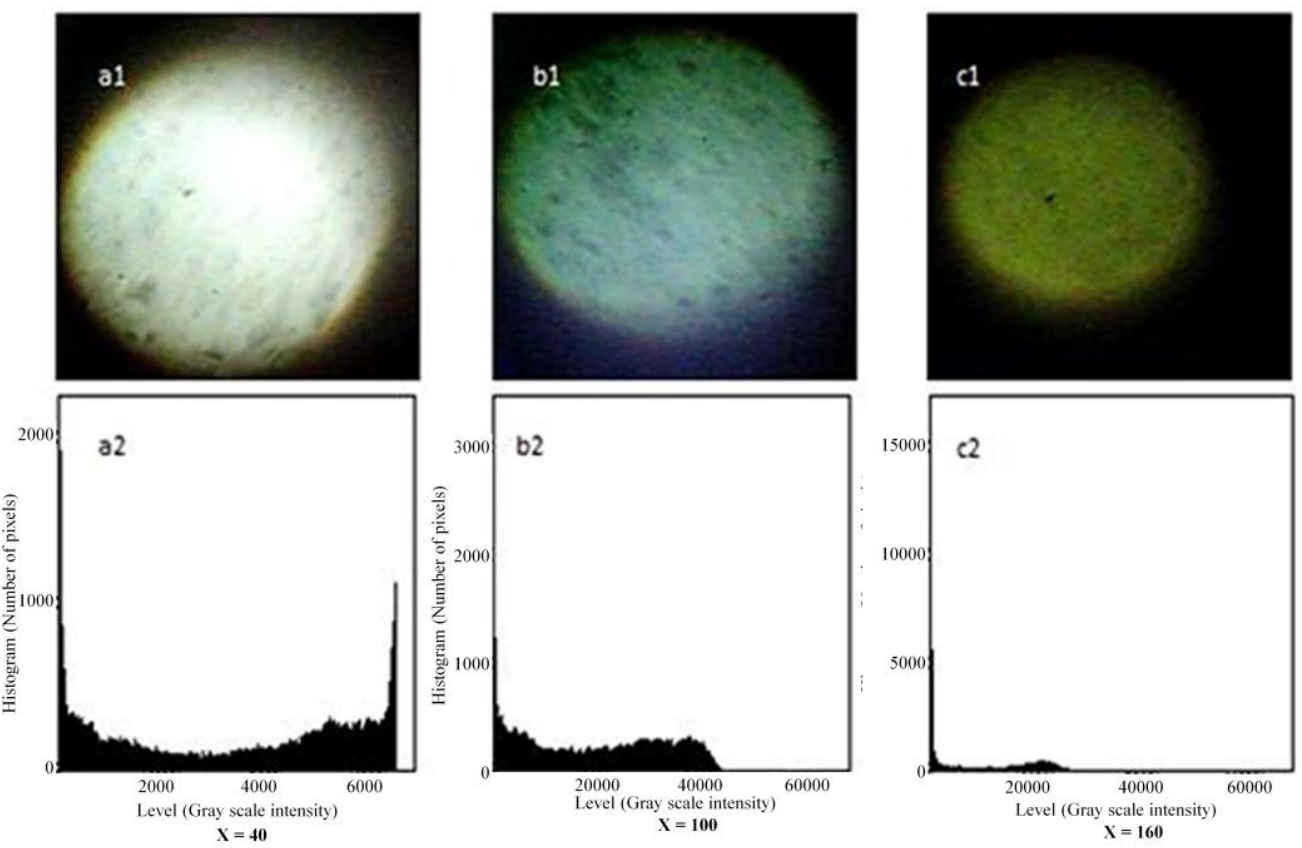

Fig. 5. The spectroscopy light images of the plant microstructure at different magnifications: a1) X40; a2) X40 histogram, b1) X100; b2) X100 histogram, c1) X160; c2) X160 histogram

Fig (1) shows the green light of images, Fig (2) shows the blue light of images, Fig (3) shows the red light of images, Fig (4) shows the white light of images and Fig (5) shows the normal microscope images (reference), all images that captured at same magnifications $(a=40$, $b=100$ and $c=160$ ) magnifications.

Then, all these images, from Fig (1) to Fig (4) were captured by modified microscopy and compared with Fig (5) that was captured by normal microscopy with 40, 100 and 160 magnifications. Also, in all those, figures (1, 2, 3, 4 and 5) lengths, were shown the processing the imaged using Origin program and histogram method, the image capturing and processing and compare between the imaged by the area under the curve and the sheep like (punchy; mutton) to know the fine accuracy and details of clear image. In Fig (1), the good image was shown, because the area under curve was bigger other images, and the shape of curve was so sharping than the others due to mechanism of image form (reflection). The other samples for all pictures were compared with normal microscope images (reference), it was found that the best result was Fig (1b), Fig (2b), Fig (1c), Fig (2c) respectively, this greatest result was achieved vigorously, by using the histogram method when, as well as, the area under the curve and the sheep of the curve together was simultaneously, calculated. Moreover, the clear image was taken when the lens magnification was 100 .

\section{Conclusions}

It can be concluded that a set of five green plant images were taken by CCD camera with different lenses and different lights. Four images were captured by modified microscopy and compared with conventional image, by different light sources (white light, laser red, laser blue, and laser green light) in the same magnifications (40,100 and 160). The images that captured by modified microscope best and clear than the normal microscope, so the modified microscope can be used to enhance image resolution. 


\section{References}

[1] C. H. G. Wright, Technical writing tools for engineers and scientists, IEEE/AIP Computing in Science and Engineering, 2010, 12, pp. 98-103.

[2] C. H. G. Wright, T. B. Welch and M. G. Morrow, Leveraging student knowledge of DSP for optical engineering, Proceedings of the 2015 IEEE Signal Processing and Signal Processing Education Workshop, 2015, pp. 148-153.

[3] B. K. Dean, C. H. G. Wright and S. F. Barrett, Biomimetic signal conditioning and light adaptation for compound vision sensors, IEEE Sensors J., 2015, 15, pp. 269 - 278.

[4] C. H. G. Wright and S. F. Barrett, Biomimetic vision sensors, Engineered Biomimicry: Bioinspiration, Biomimetics, and Bioreplication, 2013, 1, pp. 1-36.

[5] M. Aghajarian, J. E. McInroy and C. H. G. Wright, Salt-and-pepper noise removal using modied meanlter and total variation minimization, SPIE Journal of Electronic Imaging, 2018, 27, pp 1-8.

[6] R. S. Prabhakara, C. H. G.Wright and S. F. Barrett, Motion detection: a biomimetic vision sensor versus a CCD camera sensor, IEEE Sensors J., 2012, 12, pp. 298 - 307.

[7] R. C. Gonzalez and R. E. Woods, Digital Image Processing, Pearson, 20184th ed.

[8] A. Mashaer, S. Abdalseki, M. Abdelfatah, H. Hassan, The Enhancement of Blood Imaged through Confocal Microscope Using Technical Graphics Program, International Scientific Survey Journal, 2020, 3.

[9] S.L. Shaw, D. Thoms, J. Powers, Structured illumination approaches for super-resolution in plant cells, Microscopy, 2019, 68(1), pp. 37-44.

[10] T. Gevers, J. Van De Weijer and H. Stokman, Color feature detection, R. Lukac and K. N. Plataniotis, editors, Color Image Processing: Methods and Applications, 2006, p. 226.

[11] R. C. Gonzalez and R. E. Woods, Digital Image Processing, Pearson Prentice Hall, Upper Saddle River, NJ, third edition, 2008.

[12] G.G. Krebs, M. Maizel, A. Stahl, Y. Vermeer and J. T. Ott, Green light for quantitative livecell imaging in plants, Journal of Cell Science, 2018, 131, art. no. 209270.

[13] B. Jähne, Digital Image Processing, Springer-Verlag, Berlin, sixth ed, 2005.

[14] H.A. Naser and F.A. Bida, Numerical enhancement of images projected by spatial light modulator, AIP Conference Proceedings, 2020, 2290(1), art. no. 50006.

[15] A. Koschan and M. A. Abidi, Digital Color Image Processing, Wiley, 2008.

[16] K. N. Plataniotis and A. N. Venetsanopoulos, Color Image Processing and Applications, Springer 2000.

[17] G. Komis, D. Novak, M. Ovecka, O. Samajova and J. Samaj, Advances in imaging plant cell dynamics, Plant Physiol, 2018, 176, pp. 80-93.

Received: May 12, 2021

Accepted: July 24, 2021 